\title{
Engineering Rapid Industrial Revolutions for Impoverished Agrarian Nations
}

\author{
Jeffrey Yi-Lin Forrest¹, Huachun Zhao², Lawrence Shao ${ }^{3}$ \\ ${ }^{1}$ School of Business, Slippery Rock University, Slippery Rock, PA, USA \\ ${ }^{2}$ School of Economics and Finance, Jiangxi Normal University, Nanchang, China \\ ${ }^{3}$ College of Business, Slippery Rock University, Slippery Rock, PA, USA \\ Email: Jeffrey.forrest@sru.edu, huaczhao@163.com, lawrence.shao@sru.edu
}

How to cite this paper: Forrest, J.Y.-L., Zhao, H.C. and Shao, L. (2018) Engineering Rapid Industrial Revolutions for Impoverished Agrarian Nations. Theoretical Economics Letters, 8, 2594-2630. https://doi.org/10.4236/tel.2018.811166

Received: July 26, 2018

Accepted: August 21, 2018

Published: August 24, 2018

Copyright (c) 2018 by authors and Scientific Research Publishing Inc. This work is licensed under the Creative Commons Attribution International License (CC BY 4.0). http://creativecommons.org/licenses/by/4.0/

\begin{abstract}
Being able to emulate the Industrial Revolution has been the dream of many developing countries in the past one hundred plus years. However, the mainstream economics has not been able to preciously figure out what a nation should do to detonate its desired economic takeoff. Based on the recent research development in the area of development economics, this paper presents a detailed procedure on how to engineer the occurrence and evolution of industrial revolutions for an impoverished agrarian nation. This procedure is developed on top of two theorems that are first intuitively seen through the systemic yoyo model and then rigorously proven by using game theory. So, other than its theoretical value to economics, what's presented in this paper is expected to be able to bring tangible economic benefits for developing nations in the years to come.
\end{abstract}

\section{Keywords}

Light Consumer/Industrial Good, Market Fermentation, Nash Equilibrium, Systemic Yoyo Model, Textile

\section{Introduction}

In the $20^{\text {th }}$ century, many countries spent great amounts of energy and enormous efforts to modernize and to industrialize themselves by attracting foreign direct investments and by establishing manufacturing industries in major cities and commercial centers based on the most current technologies [1] [2] [3]. Although their GDP grew tremendously and the rates of investment were high, they failed to emulate the Industrial Revolution [4]. For example, in the middle of the $20^{\text {th }}$ century, many Latin American and East and Southeast Asian nations 
enjoyed annual economic growth of around or above 5\% for decades. However, they did not successfully launch any full-fledged industrial revolution [5].

By carefully studying and comparing the respective successes of launching industrial revolutions in England, the United States of America, Japan, and modern China during different times of history, and by investigating what was majorly missed by the literature on the Industrial Revolution, Wen [6] discovers that most factors that were considered crucial for kick-starting an industrial revolution in the literature, see, for example, [5] [7], such as high rates of investment in modern technology, democracy, universal suffrage, property right, etc., are actually not relevant much; instead, it is the sequence and process of industrial buildup that truly matter. To be successful, one nation has to start humbly in its rural areas within a politically stable environment. In other words, the process has to be bottom-up aiming at mobilizing the grassroots population by unleashing its hidden supply of raw labor and entrepreneurial spirits, and by organizing and transforming the population from a collection of autarkic random atoms into an organic whole of directed productive forces.

Poverty tends to be self-perpetuating, while growth tends to generate its own momentum, once growth is initially started [8]. If this initial commencement is seen as the pre-industrialization, then it must occur in the rural area [9]. Such grassroots level industrialization simultaneously helps to nurture the coordination and specialization of labor (while improving the wages and purchasing power of societal mass), and ferment the formation of a market of sufficient depth [10]. This process of development is one of the fundamental ways to help the nation to simultaneously escape from the Malthusian trap (a concept that is debatable), break the curse of food security (an issue that exists only when the nation is closed to the outside world), and detonate a full-fledged industrial revolution first in the light industry [6] if the nation only depends on its own domestic market. To this end, modern economic history indicates that for small nations, they could also detonate their industrializations through making use of the mature markets of those developed areas and nations, such as the cases of Taiwan, South Korea, etc. To an extent, modern Japan also partially benefited from such a practice by fully enjoying the mature market of the United States initially after WWII.

Considering the present moment in history, this process might be the only way for a developing nation of massive scale to succeed in its attempt with industrialization. For such a nation of massive scale, no mature market will be large and deep enough to help initiate the nation's industrialization. For example, China in recent decades attempted to modernize on the basis of taking advantage of the markets of developed nations. However, after a period of fast growth, achieved mainly though exporting, China has to in recent years actively develop its own domestic consumption in order to maintain its momentum of growth [11]. At the same time, any developing nation can no longer accumulate its first round of wealth and take the necessary time desperately needed for creating its 
colossal market, the sufficient demand, by using most of the means ever used by the Western industrial powers to develop their international markets and global supplies of raw materials [12]. And because of the current globalization of the world economy, no nation could take decades or even centuries, as in the case of England, to adequately develop its pre- and proto-industrialization and establish its domestic market before external factors start to interfere [13].

Mass production appears to meet the demand of an existing market of sufficient purchasing power and a distribution network of enough sophistication [14] [15], while the needed market and the distribution network can only be developed with the manufacturing sector and commerce function as employers and producers of wealth, and transfers resources from agriculture to industry and services [13]. In other words, mass production, market and distribution network develop and evolve simultaneously, instead of one being the cause of others. This simultaneous development of the related factors takes a long time to produce visible and tangible outcome if profits are expected along the way or requires an extremely large amount of coordination effort of resources by the government if done within a short period of time. That explains why the top-down approach to modernization and industrialization by rushing into efficient large-scale modern heavy industries, either through the Import Substitution Industrialization strategy [16], as India, Egypt, Latin America, and China did in the 1950s through 1970s, or through relying heavily on foreign loans [17], as Eastern Europe went through after the collapse of the Soviet Union since the early 1990s, or through prematurely establishing modern financial and political institutions that tend to jeopardize financial and political stability [5] [18], without first humbly going through the necessary process, has failed repeatedly [19].

This study aims to make several contributions. First, we establish two theorems rigorously on the dynamics of market competition. One theorem shows that as long as there is a profit opportunity, there will be new competition no matter whether or not the incumbent firms compete over the opportunity. The other theorem specifically indicates that as the market competition intensifies with an increasing number of players, either innovation or market expansion or both have to occur. Second, based on these two theoretical results we develop a procedure on how to engineer the kick-start of an industrial revolution in an impoverished agrarian nation by referencing the conjectures developed by Wen [6] based on four anecdotes, indeed a very small sample. In other words, we deductively derive the steps based on the general results of a theory instead of inductively using anecdotes and data mining. Third, we address the question of what can go wrong in kick-starting an industrial revolution by using the procedure developed in this paper. Fourth, we employ systems science (especially, the systemic yoyo model) and game theory to make the relationship between proto-industrialization, formation of markets, and occurrence of industrial revolution more specifiable, predictable, and repeatable so that decision choices could become more reliable. 
Among all the afore-mentioned contributions this paper makes, the most important would be the methodology developed for the study of industrial revolutions and historical events. In particular, this paper introduces and applies mathematics, systems science (especially, the systemic yoyo model, explained henceforth), and game theory to the study of a mysterious economic process. Such a need of deriving conclusions in economic history based on scientifically proven methodology has been well described by Hartwell [20] in order to make economic historians' discoveries sound, reliable, and practically duplicable, while such approach has been badly missing in the entire massive amount of literature on the Industrial Revolution.

Although written statements in daily language (based on anecdotes and data mining, as what has been the case in the past studies of industrial revolutions), mathematical equations and systemic expressions are essentially articulations of logic, there are major differences. On their own, even the most logical and precise written arguments are often inconclusive because they are linear and sequential, they cannot control for the simultaneous effect of several arguments in combination; and they are generally unable to pinpoint one optimal outcome-"equilibrium"-out of many. This end is evidenced by the various conjectures on what had caused the Industrial Revolution [8] and the countless failures of attempting to duplicate economic successes of others, for example, the Industrial Revolution of England. On the other hand, mathematics and systems science are languages, too, but they are more precise because they can feature complex "claims" or "arguments" in their totalities, both mathematics and systems science do control for the simultaneous effect of multiple variables; and they pinpoint the optimal equilibrium. This end explains why natural sciences are considered "exact", because known products, no matter what they are and how the relevant details of design and production are kept secret, can almost always be redesigned and reproduced based on how the known products function by using equations and laws of nature. In other words, our work here employs methods and models of mathematics, systems science, and game theory so that conclusions established in this paper are specifiable, reliable and repeatable for practical purposes.

The rest of this paper is organized as follows: Section 2 briefly introduces the basics of systems science and the systemic yoyo model that will be referred to in the rest of the paper. Section 3 establishes two theorems based on systemic intuition and game theory. Section 4 presents the main content of this work by detailing the steps necessary in engineering the occurrence of industrial revolutions in impoverished agrarian nations. Section 5 addresses the question of what can go wrong when an impoverished agrarian nation attempts to engineer its first industrial revolution. Section 6 concludes this paper.

\section{Systems Science and the Systemic Yoyo Model}

To make this paper self-contained, this section introduces the basic ideas and a 
brief development history of systems science, how this science complements the conventional science to form a two dimensional spectrum of knowledge and the systemic yoyo model as the playground and intuition of systems science and applications. Because business scholars are quite familiar with game theory, the less relevant details of game theory are omitted.

Historically, von Bertalanffy [21] pointed out that because the fundamental character of living things is their organization, the customary investigation of individual parts and processes cannot provide a complete explanation of the phenomenon of life. Since then, this holistic view of nature and social events has permeated the spectrum of science and technology [22]. And in the past 90 some years, studies in systems science and systems thinking have brought forward brand new understandings and discoveries to some of the major unsettled problems in science [23] [24]. Because of the proliferation of studies of wholes, parts, and their relationships, a forest of interdisciplinary studies has appeared, revealing the development trend in modern science and technology of synthesizing all areas of knowledge into a few major blocks, and the boundaries of conventional disciplines have become blurred [25]. Underlying this trend, one can see the united effort of studying similar problems in different scientific fields on the basis of wholeness and parts, and of understanding the world in which we live by employing the point of view of interconnectedness. As tested in the past 90 plus years, the concept of systems and results of systems research have been widely accepted [26] [27].

In terms of the concept of systems, similar to how numbers and algebraic variables are theoretically abstracted, systems can also be proposed out of any and every object, event, and process. For instance, behind collections of objects, say, apples, there is a set of numbers such as 0 (apples), 1 (apple), 2 (apples), 3 (apples), ...; and behind each organization, such as a business firm, a regional economy, etc., there is an abstract, theoretical system within which the relevant whole, component parts, and their interconnectedness are emphasized. As a matter of fact, it is because of these interconnected whole and parts, the totality is known as a firm, market, industry, economy, etc. In other words, when internal structures can be ignored, numbers and algebraic variables can be very useful; otherwise the world consists of dominantly systems (or structures or organizations).

When the traditional science is joined with systems science that investigates system hood, that collectively gives rise of a 2-dimensional spectrum of knowledge, where the traditional science, which is classified by the thing hood it studies, constitutes the first dimension, and the systems science, which investigates structures and organizations, forms the genuine second dimension [27]. In other words, systems research focuses on those properties of systems and associated problems that emanate from the general notion of structures and organizations, while the division of the traditional science has been done largely on properties of particular objects. Therefore, the former naturally transcends all the discip- 
lines of the classical science and becomes a force making the existing disciplinary boundaries irrelevant and superficial.

The importance of this second dimension of knowledge cannot be in any way over-emphasized. By making use of this extra dimension, the exploration of knowledge has gained additional strength in terms of the capability of solving more problems that have been challenging the very survival of the mankind since the beginning of time. Such strong promise that systems research holds relies materialistically on the particular speaking language and thinking logic - the systemic yoyo model [28], Figure 1, similar to how the Cartesian coordinate system plays its role in the development of modern science [29].

Specifically, on the basis of the blown-up theory [30], a general theory of development and evolution, and the discussion on whether or not the world can be seen from the viewpoint of systems [31], the concepts of black holes, big bangs, and converging and diverging eddy motions are coined together in the model shown in Figure 1 for each object and every system imaginable. That is, each system is a multi-dimensional entity that spins about its axis. If we fathom such a spinning entity in our 3-dimensional space, we will have a structure as artistically shown in Figure 1(a). The black hole side pulls in all things, such as materials, information, energy, profit, etc. After funneling through the "neck", all things are spit out in the form of a big bang. Some of the materials, spit out from the end of big bang, never return to the other side and some will (Figure 1(b)). For the sake of convenience of communication, such a structure as shown in Figure 1(a), is referred to as a (Chinese) yoyo due to its general shape.

What this systemic model says is that each physical or intellectual entity in the universe, be it a tangible or intangible object, a living being, an organization, a culture, a civilization, etc., can all be seen as a kind of realization of a certain multi-dimensional spinning yoyo with an eddy field around. It stays in a constant spinning motion as depicted in Figure 1(a). If it does stop its spinning, it will no longer exist as an identifiable system. What Figure 1(c) shows is that due to the interaction between the eddy field, which spins perpendicularly to the axis of spin, of the model, and the meridian field, which rotates parallel to axis of spin, all the materials that actually return to the black-hole side travel along a spiral trajectory.

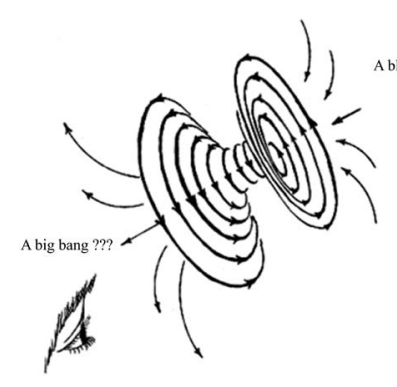

(a)

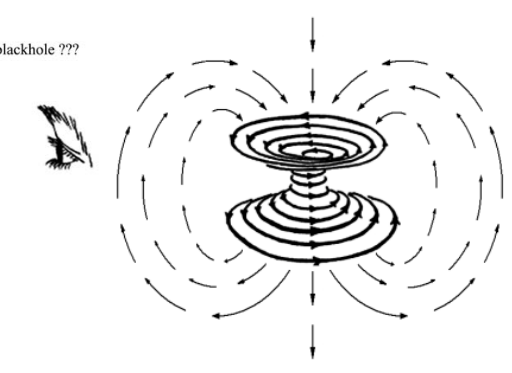

(b)

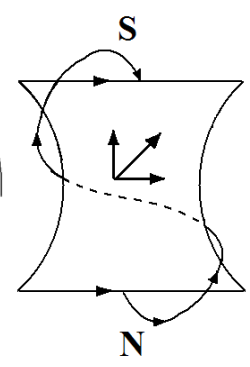

(c)

Figure 1. (a) Eddy motion model of the general system; (b) The meridian field of the yoyo model; (c) The typical trajectory of how matters return. 
As expected, this yoyo model has successfully played the role of intuition and playground for scholars who investigate the world and explore new knowledge holistically, just as what the Cartesian coordinate system did for the traditional science [11] [22] [32] [33] [34] [35]. In particular, this yoyo model of general systems has been successfully applied in the investigation of Newtonian physics of motion, the concept of energy, economics, finance, history, foundations of mathematics, small-probability disastrous weather forecasting, civilization, business organizations, the mind, among others. Along this same line of logic, in this paper we will use this model as our intuition to establish our conclusions.

\section{Dynamics of Market Competition}

Let us consider an oligopoly market that consists of $m$ firms, $m=1,2, \ldots$, providing consumers with mutually substitutable products, with their respective shares of loyal consumers. To protect their turfs while potentially increase their consumer bases, they compete over the switchers with adjustable prices charged to their customers in order to deter the potential entrance of new competitions [36]. So, assume that these firms produce their horizontally differentiated products at constant marginal costs, which is set to zero without loss of generality. Assume consequently the managements of these $m$ firms are well aware of the pricing strategies of the other firms and have established their best responses by playing the Nash equilibrium through pure self-analyses.

Speaking differently, what is assumed means that the market is in a state of mutual forbearance, where incumbent firms mitigate rivalry by dividing markets in proportion to firm strength [37]. They cede dominance to their stronger competitors in those market segments where they are less efficient, while in exchange the latter do the same in segments where the former are more efficient [38]. The firms' codependence gradually motivates them to de-escalate rivalry [39]. Eventually, the rates of entry and exit in the market decrease [40], and interfirm hostility declines [41].

Theorem 1. In the previously described oligopoly market, in the Nash equilibrium, a sufficient and necessary condition for at least one firm to enter the market profitably, as a competitor of the incumbent firms, is that the consumer surplus $\beta>0$.

The previously assumed market condition generally means that the technology involved and the relevant business operations have been standardized. So, for a new small firm to enter such a market with profit potential, it is reasonable to assume that this firm has come up with a more efficient technology and/or operation that can greatly reduce the overall business expenditure. Further assume that this small entrant uniformly randomizes its price $P$ over the interval $[0,1]$ as long as the firm could make profits on the average. Again, the constant marginal costs of this small entrant are set to zero without loss of generality.

Next, let us see intuitively why such a result holds true. To this end, let us fathom the market place is as an abstract yoyo field, and we look at the mul- 
ti-dimensional yoyo body at a distance from above either the convergent side or the divergent side, while imagine that everything here takes place in our 3-dimensional space. That is, we are looking at a pool of spinning fluid, where the word "fluid" is an abstraction of movement of all kinds of media, such as goods, information, money, credit, etc., that appear and exist in business activities. In other words, graphically one is looking at the market of concern as the pool of spinning fluid shown in Figure 2.

Associated with this end of intuition, the well-known dishpan experiment, which was initially conducted successfully by Raymond Hide [42] of Cambridge University, England, and then by Dave Fultz and his colleagues of University of Chicago [43] independently, shows that when the movement of the fluid within the rotational dish is under enough pressure created by either the sufficient speed of rotation or sufficient difference in the temperature between the center and the periphery of the dish, the pattern of uniform movement, as shown in Figure 2, will develop into the chaos, as shown in Figure 3. The number of local eddy leaves is determined either by the rotational speed or by the temperature difference or both and increases with the speed and the temperature difference.

Now, the systemic modeling and laboratory experiment suggest that the fluid nowhere within this spinning dish could avoid being disturbed by the flows, either orderly or chaotically, of the pan. And being disturbed regionally means that a local flow pattern will appear inevitably.

The practical significance of Theorem 1 is that although the market is entirely occupied by the incumbents that compete over the switchers, who at the same time are content with the existing product, there is still a chance for a new company to enter the market profitably. And the size of the entrant will be proportional to that of the market segment of switchers. In other words, as long as there is a demand, there will appear supplier(s) to fill the demand.

Theorem 2. In the Nash equilibrium, when the competition of the market grows with an increasing number of firms entering the market, the base of loyal customers for each incumbent firm will gradually diminish.

This result provides an explanation for the following phenomenon: When market competition intensifies, the landscape of the market changes faster and

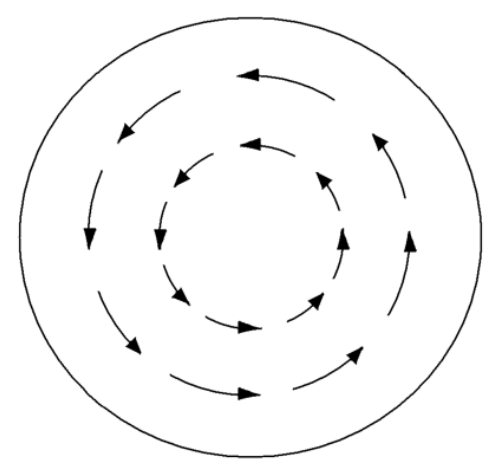

Figure 2. The systemic birdseye view of our marketplace of a previously prosperous market. 


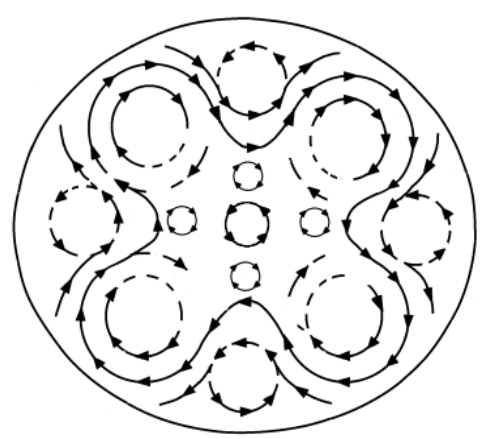

Figure 3. Asymmetric flow observed in Fultz's dishpan experiment.

faster and customers become less and less patient than ever before. In particular, when the market grows with increasing number of firms, providing additional varieties of horizontally differentiated products, entering the market, the market competition will intensify and customers become pickier than ever.

In terms of the systemic yoyo model, the market initially consisted exclusively of family-based workshops, as indicated by the small eddy leaves in Figure 4(a), where the overall circular pool stands for the fledgling market. Because the regional commerce did not actually exist or the scale was very small and could be ignored, the overall circular dish in Figure 4(a) does not spin. That is, the businesses of the region are not seen as a system; and the market is still invisible. Next, with progress in the technology of transportation and communication, the region becomes more connected through long-distance transfers of goods, information, and knowledge, the originally disconnected family-based workshops becomes connected as shown in Figure 4(b). The counterclockwise spin of the overall dish models the fact that goods, information, and knowledge are now travelling throughout the region, while original family-based workshops, the local eddies that also rotate round with the overall dish, are also serving the entire market. Such much increased demands of the market motivate the originally family-based workshops to evolve into larger scale factories of relatively more advanced technologies. At the same time, the much increased supplies of goods and services make customers spoiled so that they become less patient than ever before with anything unsatisfactory.

\section{Industrial Revolutions in Impoverished Agrarian Nations}

In this section, we look at how to possibly engineer an industrial revolution in an impoverished agrarian nation, whose grassroots population has near-zero purchasing power, by detailing particular steps that more or less have to be followed in order to successfully produce the desired outcome. After setting up the stage by describing the basic characteristics of the model agrarian nation, we list five key steps followed by detailed explanations, where all detailed explanations are derived logically from the theorems established above and/or intuitively observable from the systemic yoyo model. That is the major difference between our work presented in this paper and what are conjectured by economic historians 


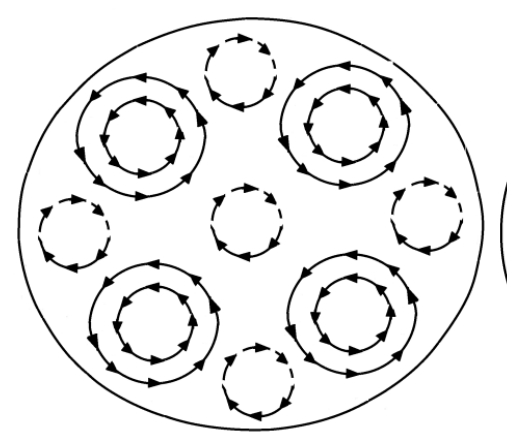

(a)

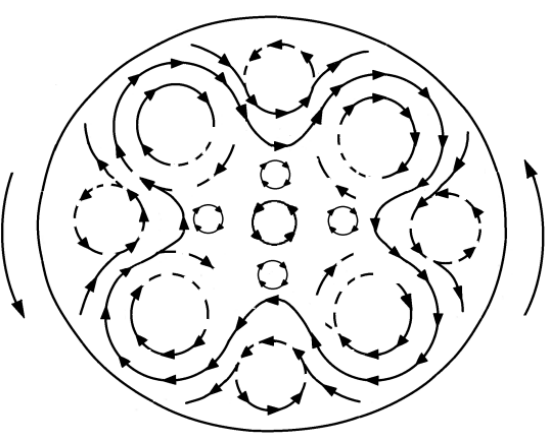

(b)

Figure 4. Market evolution in an agrarian society. (a) Family-based workshops; (b) Growing appearance of a market.

based on anecdotes and small samples of a few data points in all the references on economic history listed at the end of this presentation. And that is precisely the reason why our conclusions are more scientifically specifiable, reliable and practically repeatable than those conclusions found in the relevant literature.

\subsection{Characteristics of the Agrarian Nation}

The agrarian nation, as studied in this paper, is autarkic and unorganized without factories, cars, highways, and shopping malls. A piece of clothing is very expensive compared to the price of food, while after having bought food, people have little left for their wants no matter how elementary their lives are. For a vivid description of the preindustrial Europe, see [44].

Peasants in the agrarian nation must work long hours each day on the land, regardless of the ownership of which, be it public or private, for a related and detailed discussion about this, see [6], in order to secure enough supply of food and maintain their standards of subsistence-level living. Their leisure time and level of consumption are dictated by weather and seasons. And natural disasters and famines generally cause great pains and losses to the land and people. Because of how people are tied to their lands and how land magnitude and human population size under control signify power and wealth, rulers use all means, including wars, to gain the monopoly rights and power to expropriate others. For a more in-depth discussion on how people lived in agrarian nations, see [45]; and for how agrarian nations compete with each other, see [46].

In such a primitive society, family is the basic unit of production and exchange. Family members have to produce everything for daily lives so that there is little or no incentive to specialize and produce more than what is needed within the immediate neighborhood of the family. Without any organized market, it is risky for any family to specialize in producing just one type of household good and to depend on different sources for other necessities [15, Chapter III].

Merchants in the agrarian nation are viewed negatively and accused of calculating everything in life, including talents and friendship. (For how such negative 
views of merchants can lead to the down fall of even a great empire, see [47].) The transaction cost of contracting is prohibitive high because of the lack of any enforcement system. That makes it hard to put together large tracts of land, to ensure reliable supply of raw materials and production related supports, and to get finished products into the market quickly. And because the peasants in the agrarian nation are anarchic, autarkic, poor, and uneducated, it is prohibitively difficult for them to form cooperatives and organizations of large scales. Without a strong mercantilist government and a large merchant class to help build a unified domestic market and a well-organized commercial network in the international market, the few existing small proto-industries cannot grow to the critical level and density of the so-called proto-industrialization [48].

The lack of a large powerful wealthy merchant class leads to the government's absence in its support of forming large regional and national markets, and makes the formidable costs of social coordination impossible to overcome. Consequently, this agrarian nation does not have any unified domestic markets for goods, labor, and finance.

Despite of all the backwardness, innovative and technological changes the agrarian nation experiences would mostly take place in the agriculture sector. However, these changes are immediately translated into a much larger population without much improvement in the living standard [49], the so-called Malthusian trap or population trap [50].

By employing systemic thinking, let us model this agrarian nation as a static dish with many local, isolated eddy pools representing the family-based workshops, as shown in Figure 4(a), that provide the needs of their respective families without much trade going on with the outside world of the families. When the nation is trapped within the Malthusian poverty equilibrium, the yoyo structure of the nation stays forever the same as in Figure 4(a).

At the national level, the agrarian nation suffers from the lack of political stability and social trust, which require strong state power to build, nurture, protect, and reinforce. Both political stability and social trust represent two pillars absolutely necessary for developing a fluid national market.

In this section, we will address the following question, as modified from a similar one posed by Landes ([51], p. 274) when he critically reviews Gerschenkron's [52] influential development theory of leaping forward via adopting capital-intensive modern efficient technologies. Specifically, we will, based on the results in the previous section, provide a detailed procedure when answering the following question.

How could an agrarian country manage to acquire the knowledge and skill to overcome social, cultural, and institutional barriers to industrial enterprises and to kick-starting its industrial revolution?

The importance of this question is well described by economic historian Clark [53] as follows in terms of simply understanding what triggered the English Industrial Revolution in the $18^{\text {th }}$ century: "Explaining the Industrial Revolution is 
the ultimate, elusive prize in economic history. It is a prize that has inspired generations of scholars to lifetimes of, so far, fruitless pursuit." The massive amount of the related literature suggests that the Industrial Revolution appears to be a mysterious process of dramatic social economic changes, that only a handful of Western countries experienced in the $18^{\text {th }}$ and $19^{\text {th }}$ centuries, and that many developing nations longed to emulate the process but had failed miserably and repeatedly throughout the $20^{\text {th }}$ century. And indeed, economists are still struggling to comprehend the process and to identify its ultimate causes [1] [8] [51] [53]-[61].

\subsection{Steps of Kick-Starting an Industrial Revolution}

Industrial revolution is the name given to a movement where a new, advanced technology changes how people live, accompanied by population explosion, while the ways of how goods or services are manufactured and provided are revolutionized [62]. To the agrarian nation, industrialization represents a process that is not only a revolutionary change in the mode of production at all different levels, but also an endeavor of nation development and strengthening. The process represents a huge project of systems engineering that requires an unprecedented level of coordination among all social classes and interest groups, mobilizes the entire population of citizens, including especially the peasants, and utilizes natural, social, and political resources in ways never seen before. If successful, each round of industrialization strengthens the nation in terms of its organizational consolidation, economic prosperity, logistic capacity of projecting military forces, and influence in international politics.

Since the Industrial Revolution of England was initially recognized in the late $18^{\text {th }}$ century by the academia, many scholars have tried to pinpoint to the exact causes underneath the dramatic social-economic changes, see, for example, [8], and provided various shortcuts for developing nations to kick-start their own industrial revolutions, see, for example, [52]. However, all of these studies suffer from major flaws due to:

1) The lack of relevant data (for example, [14] attempt to fill in the gap in the literature on accounting practices of the firms that existed during the Industrial Revolution) so that a lot of causal relationships cannot be confirmed. To this end, what is important to note is that Spirtes, et al., [63] find such as scenarios when new data becomes available, the previously established causation $\mathrm{A} \rightarrow \mathrm{B}$, is reversed.

2) When potential causes are listed, they are generally a set of not related variables without any criterion that can be used to make scientifically sound judgements about which list is better and more comprehensive. Additionally, these lists are non-operational and qualitative. For example, Lipson [64] lists five reasons for England's leadership in industrialization.

3) The constraint of linear thinking (because for such a large scale social economic changes to occur, so-called causes and consequences should be interacting with 
each other and strengthening one another. So, no exact causes can be precisely located. For example, in his study of how different factors would influence each other in the stock market, Soros [65] clearly demonstrates that recognized causes and consequences actually affect each other so that none of them can be exactly seen as "causes" or "consequences".

4) A lack of beneficial applications of holistic thinking in the investigations of the Industrial Revolution. For example, Crouzet [66] builds up a picture of small differences piece by piece between the French and England's economies in the $17^{\text {th }}$ and $18^{\text {th }}$ centuries and draws the conclusion on why England experienced its industrial revolution before France. Gilboy [10] emphasizes that the factories only functioned after a large and growing demand were ready to absorb their products as fast as they were produced. And on the flip side, Wrigley [12] underlines the coal production in the $18^{\text {th }}$ century England as the cause the national economic growth. In other words, the absence of holistic thinking in the literature is the very main reason why debate on the causes of the industrial revolution has been expounding or criticizing previous studies while ending in indecision or confusion [8].

By comparing the history of 3 nations that had successfully gone through rounds of industrial revolutions, a very small sample that most surely makes the relevant conclusions scientifically unreliable other than conjectures of hot conversation topics, Wen [6] claims that the current phenomenal rise of China has shown a clear path for kick-starting an industrial revolution. At this junction, we like to point out that other than the problem of extremely small sample, [6] also suffers severely from the flaws described above. So, contrary to the existing literature, in the rest of this paper, we will utilize the results established in the previous section and in [32] to clarify what the key elements are in successfully launching an industrial revolution in the impoverished agrarian nation, where the elements do not in any way influence each other in the fashion of causal relationships. Instead, they affect each other simultaneously. Based on what is available in the literature and what can be established theoretically, we provide the following basic procedural steps for the agrarian nation to kick start its first and consequent industrial revolutions.

Step 1: Establish a long-term national goal to become wealthy and powerful;

Step 2: Develop the basic standards of moderate living;

Step 3: Engineer the market fermentation;

Step 4: Promote primary target industries; and

Step 5: Successfully round off the first industrial revolution.

\subsubsection{Establish the Long-Term National Goal}

The most successful companies from around the world always have their ambitions of becoming the best and being recognized internationally in their missions [67]. And similar to the situation of managing a large corporation, long-term development goals and strategies are absolutely needed for the agrarian nation to potentially kick start its industrial revolution in order to transform itself into a 
wealthy and powerful state. Otherwise, the life quality and security of the people have to be placed involuntarily under the mercy of the nature and/or actions of powerful nations, as witnessed in the past 250 plus years since the time of the English Industrial Revolution. As a matter of fact, throughout human history, powerful nations have always reshaped the world around them for the better or worse.

For this and similar reasons regarding quality and security of life, many developing countries have had tried their best to launch their versions of industrial revolutions in the past century or two. However, most of them failed miserably and remained in their original or even worse poverty and hopelessness [1].

By sorting through the few historical successes and much greater many failures in materializing industrialization and modernization, it is realized [6] [68] that not having any long-term national development goal of wealth creation and security assurance for the entire population is a recipe for failure. Consequent to the lack of such a national goal, the nation is not able to purposely muster sufficient support of its capable citizens to organize the grassroots population through creating jobs, maintaining social order and political stability. Without the necessary long-term goal, the national leaders and officers of different levels of the government would most likely become problems solvers instead of visionaries, planners and pursuers of a better future, busy wither solving urgent crises one after another without achieving any long-term economic and political development. Without the necessary state macroeconomic, political, and military strength, all of which need to be developed over long period of time, the nation will be unable to defend its interests against foreign aggressions, 1 et al. one competing with these aggressors. Above all, a strong government and a powerful state would possibly ensure political stability and social order of the nation and defend its interests. To this end, the modern history of many third-world countries can be used as supporting evidence and lessons. For example, one can carefully study the history of India [69] and affirm to what is stated here.

As discussed before, the agrarian nation can be naturally modelled by the dishpan in either Figure 4(a) or Figure 4(b). In either case, the distribution of the grassroots population naturally spread over the entirety of the dishpan with some individuals located within a local pool while some others along the periphery. This fact implies that in the making of the long-term national goal of development, it is practically important to note that achieving equality of people and creating prosperity for the population cannot be done simultaneously. It is because if creating wealth is modelled by establishing a local pool either in Figure 4(a) or in Figure 4(b), then some people will have to be unfortunately positioned along the periphery areas of the dish, far away from any of the local pools. So, to stimulate a massive participation of the grassroots population, creating wealth (or the local pools in Figure 4) has to be the number one priority, because the greater the number of local pools is the more people will enjoy at least some of the created wealth. 
Because the formation of the local pools in Figure 4 is the consequence of the distribution unevenness of the "fluid" within the dishpan, this systemic model implies that for the agrarian nation to evolve towards its successful launch of the first industrial revolution it has to allow market exchange to develop naturally while supplementing it with central planning. Here, the central planning is modelled by the speed of spin of the dishpan and natural development of market exchange the formation of the local pools. In practice, market exchange helps to achieve microeconomic efficiency based on productivity and competition, whereas the central planning macroeconomic efficiency based on strategic planning and aggregate management. The interworking of market exchange and central planning can be well modelled as a feedback system, where one works as the feedback mechanism for the other in order to produce the desirable output. Figure 5 describes the systemic model of a general feedback system, where Strategy 1 is market exchange and Strategy 2 = central planning, or vice versa. The feedback mechanism connects market exchange and central planning in such a way that they help adjust and improve each other to produce the desirable output.

To make such a feedback economic system work, the government needs to maintain its ability and administrative power to coordinate, discipline, manage, regulate and supervise the macro economy, to adopt, and to modify long-term development strategies for the nation. Such ability and power of the government are especially needed for maintaining a politically stable, unified national market, which is sufficiently large, organized, violence-free, robbery-free, and credible. And when it is time to build heavy industries that involve the construction of necessary infrastructure and national security, such ability and power will once again be called upon to mobilize and organize resources.

At the same time, the government needs to help shift the national ideology, whatever it is currently, toward commerce and commercialism, and to encourage profit-(productivity)-seeking and arbitrage behaviors in order to eliminate inefficiency and firm-level resource misallocations by making use of the market mechanism. What would happen if the government does not do this? The fate of the Soviet Union is the answer, where the government only realized the importance of commerce and commercialism right before its collapse [47].

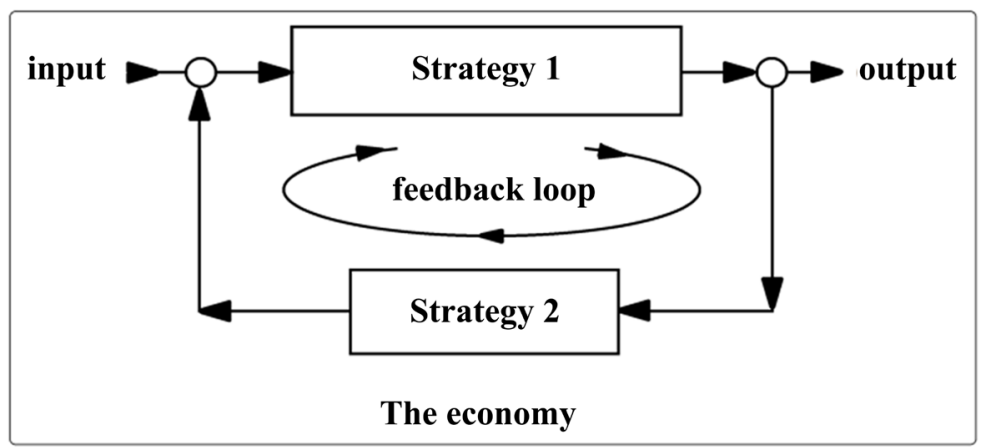

Figure 5. The feedback mechanism between two interacting strategies. 


\subsubsection{Develop the Basic Standards of Moderate Living}

In the modelling of the agrarian nation in Figure 4, as a market of scale starts to form, more and more "fluid particles" have to be relocated in order to support the strengthening spin of the local pools. This systemic intuition implies that before anything else, what is very important as the first step towards kick-starting a full-fledged industrial revolution is to increase the production of crops in order to free up additional labors from the land. That can generally be accomplished by launching a primitive agricultural revolution through a combination of policies and technologies. The former is a role played by the central planning and can deal with such details as land use or ownership, freedom to decide what to plant, etc. (For example, Crespi et al. [70] show that tax policies really impact firm level investments in developing countries by looking at the case of Argentina.) And the latter represents a role played by the market exchange. Because of that, only technologies appropriate to the level of skills of the peasants and their purchasing power will be introduced one after another starting from elementary ones to more advanced levels over time. (For example, Kang et al. [71] demonstrate that firms with low technological capability maintain $\mathrm{R} \& \mathrm{D}$ under positive shocks and decrease R \& D under negative shocks.) Practically speaking, what is concluded here is the fact that the agricultural output has to be increased to such a degree that a critical proportion of the farm labor can be spared from the land to participate in the production of industrial goods and commercial activities without jeopardizing the secure supply of food.

Under the effect of central planning, spare labors from the land and the idling labors during off seasons of the farms will be organized to construct and improve the infrastructure, consisting of village-level irrigation systems, road networks that connect villages, townships, and cities, and power grids. The irrigation systems make the agricultural sector more resilient against adverse weather conditions, which directly benefit the food production. The road networks help expand local exchanges within individual villages into a regional and national market, within which goods are ordered and delivered over long distances in a timely fashion. And electricity, as a powerful resource of energy, opens up additional possibilities and opportunities, while improving the overall quality of life. Because all of these projects need to be organized, coordinated, and possibly financially supported by the local, regional, and the central governments, the central planning of the government plays its role.

As what is shown in the dishpan experiment, the flow pattern in Figure 4(a) evolves into that of Figure 4(b) gradually with the increasing difference in terms of the acting forces on the "fluid's" particles between the periphery and the center of the dish, it means that the national economy starts to emerge when a banking system starts to appear across the land (where money is seen as the "fluid" in the experiment), while village firms that produce light industrial goods for households' use are established with locally available labor. Because the movement of money can be modelled by the flow-pattern of the "fluid" in the 
dishpan experiment and village firms the seeds of local pools in Figure 4(b), it can be seen that the initial tiny firms will eventually play the role of catalyst of the forthcoming rural industrialization.

To make sure the difference between the periphery and the center of the dish keep increasing in order to eventually lead to the state shown in Figure 4(b), beyond encouraging commerce and merchant activities, especially in the countryside, the government has to directly participate in them through using all sorts of governmental resources in order to make commerce flourish across the countryside and within cities. With commercialization promoted by the government throughout its tree-like branches, the grassroots population, within which the branch tips of the government are deeply entrenched, will be mobilized based on unified beliefs and promoted values. So, consequently, the primitive rural area firms will in due course evolve into a large-scale rural industrialization that will in turn lead to the formation of colossal, unified domestic markets of light consumer/industrial goods and labors.

The key in this step is to mobilize the grassroots population by promoting a new set of elevated basic living standards through providing freedom in land use, encouraging commerce, and pushing for the formation of unified domestic markets. Here, although the formation of the markets have to take a long time, as in the case of England [8], the United States [72], and Japan [73], or spend colossal amount of coordination effort, as in the case of modern China [74], the determining action the government has to take is to encourage commerce and provide a degree of freedom on how the citizen can conduct their respective businesses. To this end, Theorem 1 implies that with the increasing purchasing power of the grassroots population, responding to the growing demand, firms of growing scale will automatically emerge based on entrepreneurial spirits; and with rising exchange rate of money and goods, local and then regional markets will appear, which will be soon followed by the formation of a national market of light consumer/industrial goods. The details to this end will be addressed in the following subsections.

In terms of the systemic yoyo model, what this step accomplishes is to tighten the association between the government and its people. In Figure 6, the axis of spin represents the government and the layers of the spinning field the people of the grassroots population. In this model, the government (the axis of spin) exists because of the people (the spinning field). By helping to connect the people through creating colossal, unified domestic markets (the meridian field that holds the eddy fields together), the body of the yoyo structure of the nation becomes more solidified than ever before.

\subsubsection{Engineer the Market Fermentation}

When the speed of spin of the dish in Figure 4(a) increases, the originally isolated local pools will gradually become connected with one another and start to interact with each other as shown in Figure 4(b). This fact implies that with unified beliefs of the people, as promoted by the government at all levels, and the 


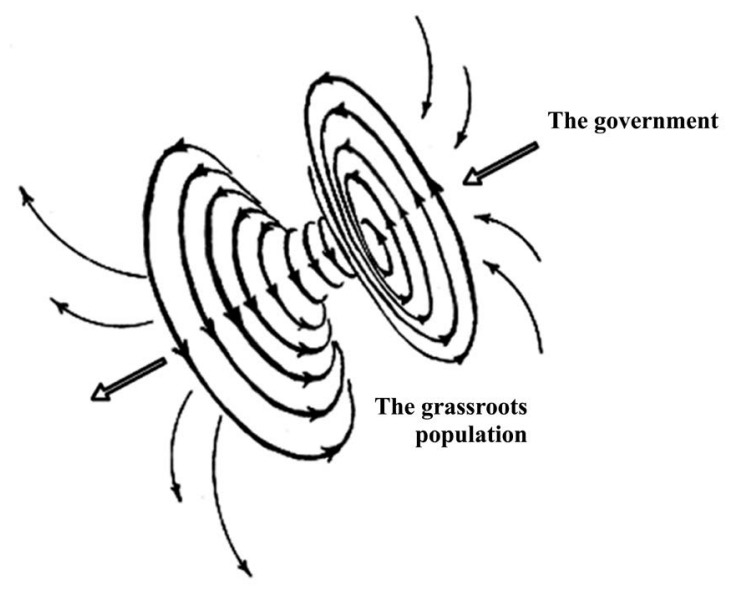

Figure 6. By closely associating with the people, the yoyo field of the nation becomes energized.

administrative power of local governments, as mandated by the national government's central planning, peasants from different families will be organized to work in teams in order to engage in coordinated production and to share profits and risks, the local pools in Figure 4(b). Although the initially established rural factories across the entire countryside are most likely of primitive form, the initially strengthening local pools developed from those in Figure 4(a), they still require capital beyond a peasant's annual family income and fundamental trust among workers and organizers. Because the local government helps to establish and reinforce a degree of social trust, a large enough proportion of farmers and peasants will be able and willing to pool their savings together as the initial investment (both cash and other forms of assets) in a business venture that by design is collectively owned with profits and work opportunities equally or proportionally shared among village families. In other words, the initial isolated local pools, in Figure 4(a), are able to grow through the efforts of the leadership of local governments so that the prohibitive transaction costs of contracting in the agrarian society could be overcome.

Because the spin of the dishpan in Figure 4 affects the entire dish, it means that although the agrarian nation does not have a wealthy, powerful class of merchants that could play the role of market creators, local government officials have to fill into this missing link. Here, the spin of the entire dish models the role of the national government, while the local movement along the overall spin represents the role of the local government. So, this modeling implies that any local government official, who is incompetent in finding ways to bring material wealth to local people, need also be removed from office under fierce intra-national competition for economic success in villages, townships, counties, cities, and regions. And in really, such practice will effectively turn officials of all levels of the government into a highly motivated class of public "merchants". And through merit-based competitions with neighboring villages, townships, cities or regions emerges a new generation of very capable business-minded gov- 
ernment administrators. They help create local, regional, national, and international markets for local businesses through supporting village firms in whatever means necessary, such as low taxes, cheap land, attraction of outside investment, advertisement of local products, negotiation of business deals, construction of distribution networks, so on and so forth.

As a part of the force that spins the dish in Figure 4, to materialize the national mission (to make the dish spin faster than before), officials at all levels of the government have to provide critical middleman services to village firms, such as providing credit, obtaining loans, enforcing payments, supplying commercial information, organizing industrial parks and trade exhibitions, engaging in negotiations for the supply of raw materials and intermediate goods, etc. And when necessary, they could even coordinate the absorption of inventories and smooth supply-demand shocks to firms. Very importantly, these officials coordinate organized peasants in their spare time to build and improve the local infrastructure, such as the local road network, irrigation systems, etc. In other words, local governments of all levels, coordinated by the central government under the national mission, facilitate the creation and expansion of firms, large or small, and speed up the process of market creation.

With the increasing speed of spin in Figure 4, the originally stagnant, isolated local pools (Figure 4(a)) will grow larger and become connected and start to interact with each other. That indicates that with the combined effect of the peasants' desire to improve their subsistence-level farming income and the government officials' mandate to develop their local economies, rural industries will flourish. And then, the agrarian nation will soon experience rapid proto-industrialization and economic takeoff. In particular, the rural industrialization offers an ever-increasing variety of consumption goods, promotes demand for diversified agricultural goods based on the growing purchasing power of the population, and absorbs the surplus labor in the countryside. Such development provides incentives for efficient farming through innovation, profit seeking in business dealings, and entrepreneurship to create new opportunities. All of these translate into increased agricultural productivity with less labor, and expand people's preference beyond simply making babies to also making goods and to accumulating material wealth. This end helps the nation to escape from the Malthusian trap.

Summarizing what has been discussed above based on the systemic yoyo model and the theorems established earlier, it can be readily seen that to successfully engineer the market fermentation, although the nation may still largely remain agrarian and poor and still rely heavily on primitive technologies in the rural industrial sector, the key includes the following:

1) The national government pushes for a strong mercantilism ideology and actively participates in the proto-industrialization;

2) Commercial activities in both urban and rural areas are encouraged and protected by the government in domestic and international affairs, where rural 
industries are distinctively different from urban craftsmen workshops with the latter satisfying local and restricted markets whereas the former producing to satisfy national and international markets [75] [76];

3) Draw and transform a large pool of the autarkic peasants into cooperation-based manufacturing and industrial organizations; and

4) Create sufficiently high incomes and purchasing power for the grassroots population.

The significance of market fermentation is that it simultaneously evolves with the appearance of mass production, which jointly helps the agrarian economy to transit forward into a mass-production economy. The benefits of this step include:

1) Stimulate the commercialization of agricultural products, which simultaneously raises people's purchasing power and develops markets of exchange without jeopardizing secure supply of food, which naturally leads to the adoption of mass productions;

2) Transform the originally atomic, autarkic, uneducated peasants into organized, skilled labor (For example, Dosi et al. [77] investigates patterns of "learning by doing" at the product level in a catching-up country, India. Their evidence suggests that performance improvement over time is not just a by-product of repetition of the same production activities, but rather shaped by deliberate firm learning efforts), which in turn helps to remove the financial and technological barriers of expanding small-scaled workshops of primitive technologies into factories and other modern production facilities;

3) Motivate regional specialization and domestic and international trade based on local comparative advantages; and

4) Enhance government revenues needed for further infrastructural development, leading to the creation of advanced distribution systems, supply chains, and industrial clusters. That will naturally lead to the arrival of mass production-the first Industrial Revolution.

The first and second benefits listed above are extremely important, because in terms of our systemic yoyo model, only when the dish in Figure 4 spins at a speed above a critical level, the desired pattern of the "fluid" movement in Figure 4(b) can be created. In other words, only by simultaneously having massive industrial employment, a large class of entrepreneurs, and a market of sufficient purchasing power, the process of industrialization can be sustained with increasing financial strength and technological upgrading. Otherwise, the nation will fall into the middle-income trap, such as what happened to the Latin American nations [78].

In terms of the systemic yoyo model, what this step accomplishes is to construct and strengthen the meridian flows (a market with sufficient purchasing power) of the yoyo field (the nation) as shown in Figure 1(b) and Figure 6 that, in fact, help make the spin of the yoyo body stronger and faster. As what Theorem 1 spells, when a market of goods exists, new firm(s) will emerge to satisfy 
the market demand, which in turn makes the competition of the market more intensified.

\subsubsection{Promote Primary Target Industries}

As the originally isolated local pools in Figure 4(a) starts to expand and interact with each other, evolving towards that in Figure 4(b), it indicates that both the rural industrialization deepens and a larger market of manufactured goods and services develops. Together, what is meant is that the average households' income grows and the purchasing power of the developing market increases. Within the simultaneously stimulating interactions of these two factors, profit-driven responses from the existing family-based firms are invited and encouraged. So, quickly, the market fermentation and organizational development of the manufacturing sector jointly transform part-time peasant workers into full-time workers, and village firms into large-scale factories. That is when a great number of craftsmen and merchants are simultaneously engaged in large-scale mass production, mass distribution, and mass exchange in order to win competition for market shares.

As the transition from the pattern in Figure 4(a) to that in Figure 4(b) evolves gradually, it means that the depth of the market of manufactured goods, especially the purchasing power of the market players, and the mastery of skills of the newly converted peasant-workers need time to improve. That end indicates that to successfully trigger a revolutionary transition from family-based, autarkic, agrarian production to factory-based industrial mass production, the government needs to help relevant parties to focus on one or several primary target industries and a class of light industrial goods, which are income elastic and do not initially require much capital input and know-hows, for promotion. And, among all economic activities, the production of food, cloth, and shelter is most basic for human survival. In comparison of these three necessities of life, spinning and weaving are not constrained by such conditions as weather, season, and daylight and can be mechanized much easier by using simple low-cost tools than growing crops and building shelters. And, among all natural fibers, cotton is the one that can be most easily manipulated. At the same time, the textile market is potentially the largest and most income-elastic when compared to other light consumer goods, such as jewelry, pottery, furniture, etc., as Deane ([79], p.66) puts: “(Cotton textile) was cheap enough to come within the budget of the lowest income groups and fine enough to be desired by rich as well as poor; it was salable in tropical as well as in temperate climates; ..." Hence this market can grow rapidly with income and easily support mass production and stimulate innovation under competition. So, based on this analysis, the textile and clothing industry should be chosen as one of the agrarian nation's primary target-industries for promotion, because this industry bears little technological obstacle of entry and relatively low entry costs, while it enjoys a huge domestic and international market. Accordingly, special government agencies need to be established to facilitate, intermediate, and regulate the chosen primary target in- 
dustries to comply with the relevant international market rules and to cope with the corresponding competitions.

Like the textile industry described above, other chosen primary target industries should also be of the following characteristics: the production can be easily divided into many intermediate stages, and each stage production is simple enough that workers without any or much training can accomplish. Next, firms can identify those production stages that require mechanical motion. Such repeatable physical movements are the part of the production process that can be most easily replaced by preliminary machines (tools) operated by natural power (the human body, animals, or water flow). As a domino effect, when one particular production stage is mechanized, it immediately creates demand for mechanization of other production stages in order to keep pace so that the demand/supply of intermediate-stage goods can stay in synch. So, eventually, the entire production process becomes mechanized. This end is supported by the quick appearance of the interacting local pools in Figure 4(b) soon after the originally isolated local pools start to grow.

To summarize, the key accomplishments of this step include:

1) The preliminary basic level effort of coordination of the government on the expansion of small-scale firms and the development of market of manufactured goods is gradually brought up to much higher levels with increasing tax revenues and growing profits of the firms and the market;

2) Both the mechanization of producing light consumer/industrial goods and the increasingly more vibrant market stimulate each other to become more sophisticated, producing more skilled workers, much elevated wages, reduced prices, and deeper, wider, much more dynamic, causing a more densely knitted commercial network to appear; and

3) To meet the expanding demand of consumption, there are growing needs to discover and invent new varieties of the existing goods, new consumer goods, intermediate goods, and even raw materials. That together powers the development of capitalism and the first industrial revolution.

As what Theorem 2 indicates, as the market competition intensifies, newer varieties of existing products and newly innovated products need to be introduced in order for companies to maintain and expand their market shares. At the same time, overseas markets have to be explored and entered in order to develop the necessary depth and magnitude of the overall market of goods so that further division of labor and large cooperation continue to be profitable.

In terms of the systemic yoyo model, this step completes the development of making the yoyo field of the agrarian nation that was initially barely spinning revolve stronger and faster so that its meridian field reaches into the fields of many other yoyo fields. This systemic intuition is depicted in Figure 7, where the yoyo body located at the center becomes solidified and influential over other yoyo bodies.

What is analyzed in this subsection indirectly implies that if the domestic 


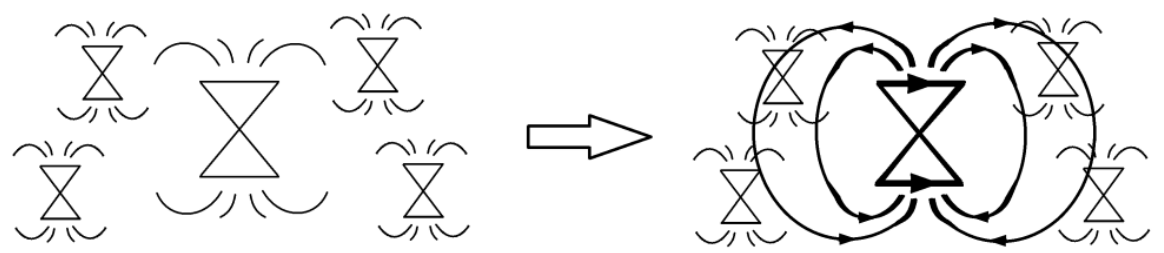

Figure 7. A backward agrarian nation evolves into a wealthy and powerful society.

market of the agrarian nation does not have enough magnitude, then it would have to rely more heavily on the international market. That explains why in the current world, when a nation is small, its economy will be greatly affected by politics of large foreign economies.

\subsubsection{Round off the First Industrial Revolution}

When the nation's capacity to mass-produce light consumer/industrial goods reaches a threshold level, it simultaneously indicates that the nation's domestic and foreign markets have developed immensely. At such a stage of development, the following comes into play.

First Law on State of Motion [17]: Each imaginable and existing entity in the universe is a spinning yoyo of a certain dimension. Located on the outskirt of the yoyo is a spin field. Without being affected by another yoyo structure, each particle in the said entity's yoyo structure continues its movement in its orbital state of motion.

In particular, this law implies that the development momentum of the manufacturing sector and the market will continue, making the demand and purchasing power of the nation for energy, locomotives, infrastructure, and machinery equipment become colossally great. That in turn makes the mass production of heavy industrial goods immensely profitable. In other words, a development-momentum-driven boom in the industrial trinity of energy, locomotive power, and transportation infrastructure appears. That is when a Rostow [4] moment of economic takeoff is bound to happen.

The first industrial revolution is rounding off when machineries and other things of such sophistication are mass produced by means of machineries [51]. If at this stage of economic development the nation can join a major international trade organization, such as the World Trade Organization (WTO), then it will enter the phase of heavy-industrial buildup, supported by its domestic savings and international market demand. Immediately following that will be the mass production of chemicals, cement, electricity, steel, metal products, combustion engines, trucks, automobiles, ships, highways, railroads, high-speed trains, and agricultural and textile machineries, as well as assembly lines and machine tools for producing all sorts of light industrial goods. And, onward it goes the nation now is at the doorstep of the second industrial revolution.

Summarizing what is discussed throughout the five afore-described steps, we can see that when the originally primitive economy is purposefully affected by the national government, the economy will grow and the market of goods and 
services will deepen simultaneously, as indicated by the first law on state of motion. That makes the relatively old methods of manufacturing become inadequate. That is, once the original raw labor is divided according to divisions of production stages, and market demand and supply are stimulated concurrently, the market demand and supply will then enter into a horserace to create each other. Accompanying this escalating intensity of race, the scale of production is further and further mechanized; and a greater and greater market of manufactured goods developed. As the domestic market becomes saturated, the established productive capacity looks outward into different corners of the world to create new markets. The formation of new markets makes another round of mechanization and new technology adoption profitable. Additionally, a radical change in the production process in one area of an industry creates demand and incentives for similar changes in other areas. So, growth leads to more growth; expansion creates more expansion, as what the first law on state of motion implies.

Looking back into the world history of economic development, it can be readily seen that virtually all developed nations more or less followed the same path paved by the British to successfully kick-start their first industrial revolution. However, China's recent economic development is still seen as a surprise and unexpected, because the English Industrial Revolution over 250 years ago was not fully understood until now. At the same time, the case of modern China vividly shows the fact that although a particular nation of concern might be very different from each of the developed countries, for example, in terms of political systems, levels of technological sophistication, purchasing powers, etc., the nation could still successfully engineer its industrial revolutions from start to finish within a relatively short period of time.

\section{What Can Go Wrong When Attempting to Engineer a Rapid Industrial Revolution?}

Comparing to redesigning and reproducing a physical product with known features and functionalities, recreating an event and a process that involve people is much more difficult, because some of the underlying characteristics of the people employed in the recreation will be surely different from those of the people involved in the original event and process [80]. In this section, let us look at where an attempt of engineering an industrial revolution in our model impoverished agrarian nation could go terribly wrong by analyzing the previously listed steps.

For Step 1 given above, things can easily go wrong at several places.

First, adopting a long-term development goal can be practically difficult or impossible. For example, if the agrarian nation is mostly controlled by various interest groups, then any development goal that aims at kick-starting an industrial revolution and elevating the nation onto a new state of wealth and power will be in conflict of some sort with at least some of the interest groups. (To this 
end, Wielicka-Regulska et al. [81] shows that for such a small-scale issue as food consumption, different objectives lead to conflicts in food choices, new food product design and development.) Similarly, the necessary shift in the national ideology towards commercialism can be extremely difficult to accomplish.

Second, maintaining political stability is easier to say than done. National stability of any imaginable kind in the modern era of globalization is greatly influenced by both internal and external factors. The former could be closely related to how different interest groups interact with each other, while the latter could be consequences of international politics. For example, Pinto Barbosa et al. [82] analyze how political stability depends on various economic factors and find that fluctuations in interest groups' economic capacities and in their abilities to engage in rent-seeking or predatory behaviors create periodic incentives for the groups to renege on their social obligations. And Asongu et al. [83] look at the effect of globalization on governance in 51 African countries for the period 1996-2011 and find that social globalization improves political stability while the effects of globalization on the rule of law and institutional governance are not significant. So, certain kind of internal unity is needed for soothing internal rivalries, while national strength is necessary for fending off external bellicosities. Without the necessary internal unity and national strength, it will be difficult to mobilize capable citizens to make investments and to create jobs so that the grassroots population can be effectively organized.

Third, developing the necessary national macroeconomic, political, and military strength could potentially take a long time, during which many things, both internally and externally, could go wrong [84].

Fourth, when market exchanges are encouraged, the issue of equality could potentially become problems [85]. So, central planning should be appropriately introduced to help ease the tension between different classes of labor. In other words, the feedback mechanism between market exchange and central planning could be off balance readily without the intervention of a capable government.

If everything in Step 1 goes as desired, then in Step 2, what could potentially go wrong includes at least the following. First, the market exchange could not function ideally due to various interferences [86]. So, the national market cannot grow as initially foreseen in terms of its coverage, maturity and sophistication.

Second, the hierarchy of the government system cannot work as an organic whole in its push towards realizing the national goal [87]. Such dysfunction of the government would lead to many undesirable consequences, including, but not limited to, 1) the necessary infrastructure cannot be either initially constructed or improved regularly so that food supply cannot be secured, and villages, townships, and cities cannot be connected by roads and power lines. 2) A national banking system cannot either be organized or function ideally. So, existing village firms cannot be expanded, while it is hard for new firms to get launched, all due to lack of financial support and the necessary flows of money. 3) Governmental resources cannot be directed towards the improvement of 
commerce across the countryside and within cities. And, 4) Due to lack of social trust, unified beliefs, and promoted values the grassroots population cannot be mobilized.

For Step 3, what might go wrong include, but not limited to, the following: 1) Raw labors from rural areas cannot be organized to work in teams due to various reasons, which include most likely the lack of social trust [88]. 2) Market creators do not exist so that large-scale market exchange and adequate distribution network cannot be developed [89]. 3) The purchasing power of the grassroots population could not be raised, causing a stagnant development in the depth of the national market. This end is supported by, for example, Lakshmanan and Hansen [90], who explore possible equilibrium distributions for large retail trade centers in the Baltimore metropolitan area. These authors establish that there exists a balanced distribution in which the size of centers is related to their drawing power, which in turn depends on the distribution of purchasing power of the area and the transportation facilities and for trip-makers.

For Step 4, what could go wrong include, but not limited to, the following.

1) Profit-driven behaviors could not be successfully encouraged due to the inertia of conventional beliefs [47]. That generally causes stagnation in employment and wages and the purchasing power of the national market. (For example, Slater and Narver [91] show that to achieve superior performance, which directly related to employment and wages of employees, a business must develop the capability of consistently deliver superior value to customers. That capability is a consequence of profit-driven efforts.) Therefore, the market fermentation and organizational development of the manufacturing sector are comprehensively affected adversely.

2) The government does not have the vision on what primary industries to target on and which class of industrial goods to emphasize on. In such a case, the agrarian nation within the current trend of globalization could conveniently develop its economy by playing supporting roles for the developed nations without much chance to develop its own independent future. When this happens, the economic security of the nation will be tightly controlled by others. This fact can be readily shown by simply looking at those countries where the economies are mostly driven by exporting natural resources.

3) Government officials become very corrupt so that they lose the trust of the people. When this happens, the government will no longer be able to coordinate resources, leading to declining tax revenues and lowering profits of the existing firms and the market. In particular, let us look at the case that public services and goods provide necessary inputs into productive activities. In our present time, governments generally finance these inputs through taxes collected from their communities. When such a process is greatly affected by bureaucratic corruption, the relevant public expenditure becomes inefficient. To this end, Del Monte and Papagni [92] investigate the long-run consequences of such corruption and find in the Italian case that the effect is significant. 
When the development momentum of the manufacturing sector and the market cannot be maintained due to whatever reason, the process of industrialization will have to stop, if it ass ever been started. Hence, no industrial revolution will be in sight.

\section{Conclusions}

Other than the theoretical reasons (as established in this paper), the intuition of why our established procedure in this paper will work in real life is that for any nation, its government and grassroots population coexist in such a way that the working of the former is more or less a reflection of the state of the latter. Figuratively in Figure 6, the axis of spin of the yoyo structure of the nation cannot dictate how the grassroots population should drastically change its state of motion. In other words, the former is determined by the latter; and if the former wants the latter to change in certain particular way, then the former has to first mobilize the latter so that both of them evolve correspondingly. That explains why for a nation to kick-start its first industrial revolution, both the government and the grassroots population have to be on the same page while applying an appropriate bottom-up approach.

In particular, our theoretical results in this paper show that after a primitive market is formulated, competitions of the market will naturally intensify, which in turn encourages innovation in production and expansion of the market. That will help kick-start the awaited industrial revolution. However, developing a mature market and network of distribution in the first place either takes a long time, if it is done naturally without heavy involvement of the government, or requires a huge amount of coordination effort if the government is involved and wants it to be done quickly. In either case, maintaining the market and the network of distribution requires constant government regulation and monitoring and increasing purchasing power of the market participants. That explains why any top-down approach will not work (see [32] for how a torn nation could appear), be it simply starting industrialization in large commercial cities, or blindly adopting modern, efficient production technologies, or sightlessly implementing a liberal financial reform, before having created the proto- and light-industrial manufacturing sector, market, and distribution network, and before having developed amass demand (purchasing power) and the capability of mass supply of heavy-industrial goods that reinforce each other.

In the contrary, a bottom-up approach means that an eventually successful industrialization is started in the rural area with the grassroots population, where the development of large-market oriented workshops and light industries that produce humble, labor-intensive, and low-value-added products is encouraged in order to meet the needs of the grassroots populace [9]. Here, by a large market, it means such a market that can absorb the massively produced goods. So, if the domestic market is not sufficiently large, then the nation has to actively become a part of a much larger international market. This end explains why 
small economies have to be part of a major international market in order for their economic development to take off. This end is similar to why geographically some nations are huge while most other nations are small [32].

Because the eventual success is the consequence of a giant coordinated effort by many, many participants and synchronized allocation of resources, the government has to play an active role. The government needs to be pushing for a mercantilist ideology, have the administrative power to mobilize the local government agencies, be willing to support the creation of markets (both domestic and international), manage domestic savings and credit supplies, and build infrastructure [93].

In terms of the innovative methodology developed in this paper, it consists of a particular way for researchers to utilize their imagination and intuition, similar to the situation of how Cartesian coordinate system (consisting of several crossing number lines) plays such a role in entire modern science, followed by means of rigorous reasoning, two key reasons for the success of calculus in the scientific history [33]. Because of this reason, this specific methodology is expected to be widely useful in the study of historical economic events. To this end, first, as a matter of fact, economic historians have actually realized the deficit in their language-based expositions [8] [20] and called for the introduction of economic analysis and quantitative methodologies into the investigation of economic history. Second, it has been a well-known fact in science that conjectures, even although they might be called theories by relevant researchers, developed inductively on anecdotes and data mining is not reliable and often misleading. For example, from the anecdotes or empirical evidence that $0^{2}=0$ and $1^{2}=1$ (there are many similar examples in mathematics that illustrate how inductive reasoning fails), one could easily conjecture a general theory that $n^{2}=n$, for any national number $n$, which is evidently incorrect.

Therefore, other than the theoretical and practical significance of the results developed here, the most important contribution this paper makes to the literature perhaps is the illustration on how principles and methods from systems science (especially the yoyo model) and game theory can help understand economic events and processes of related developments. So, practical benefits of such brand new understandings can be potentially materialized.

For future research, we like to see how our established procedure can be employed in practice so that relevant details can be fine-tuned and others added or removed.

\section{Acknowledgements}

This work is partially funded by a major project of Social Science Foundation of China (16ZDA014) and Social Science Foundation of Jiangxi Province (15YJ15).

\section{Conflicts of Interest}

The authors declare no conflicts of interest regarding the publication of this paper. 


\section{References}

[1] Acemoglu, D. and Robinson, J. (2012) Why Nations Fail: The Origins of Power, Prosperity, and Poverty.

[2] Breslin, S. (2009) State Led Development in Historical Perspective: From Friedrich List to a Chinese Mode of Governance? The Beijing Forum, Beijing, November 2009.

[3] Chang, H.J. (2003) Kicking Away the Ladder: Development Strategies in Historical Perspective. Anthem Press, London.

[4] Rostow, W.W. (1960) The Stages of Economic Growth: A Non-Communist Manifesto. Cambridge University Press, Cambridge, UK.

[5] Studwell, J. (2013) How Asia Works: Success and Failure in the World's Most Dynamic Region. Grove Press, New York.

[6] Wen, Y. (2016) The Making of an Economic Superpower: Unlocking China's Secret of Rapid Industrialization. World Scientific, Singapore. https://doi.org/10.1142/9885

[7] Lipton, M. (1977) Why Poor People Stay Poor: Urban Bias in Developing Countries. Temple Smith, London.

[8] Hartwell, R.M. (ed.) (2017) The Causes of the Industrial Revolution in England. Routledge, London and New York.

[9] Mendels, F.F. (1972) Proto-Industrialization: The First Phase of the Industrialization Process. The Journal of Economic History, 32, 241-261. https://doi.org/10.1017/S0022050700075495

[10] Gilboy, E.W. (1932) Demand as a Factor in the Industrial Revolution. First Published in: Cole, A.H., et al., Eds., Facts and Factors in Economic History, Harvard University Press (1932), and then in: Hartwell, R.M., ed., (2017), The Causes of the Industrial Revolution in England, Routledge, London and New York, 121-138.

[11] Forrest, Y.L.J. and Tao, L.X. (2014) Investment and Employment Opportunities in China. CRC Press, New York, NY. https://doi.org/10.1201/b17728

[12] Wrigley, E.A. (1962) The Supply of Raw Materials in the Industrial Revolution. First Published in The Economic History Review, Vol. XV, No. 1 (1962), and then in: Hartwell, R.M., Ed., (2017), The Causes of the Industrial Revolution in England, Routledge, London and New York, 97-120. https://doi.org/10.2307/2593286

[13] Deane, P. (1957) The Industrial Revolution and Economic Growth: The Evidence of Early British National Income Estimates. First published in Economic Development and Cultural Change, Vol. V, No. 1 (1957), and then in: Hartwell, R.M., Ed., (2017), The Causes of the Industrial Revolution in England, Routledge, London and New York, 82-96.

[14] Fleischman, R.K. and Parker, L.D. (2017) What Is Past Is Prologue: Costing Accounting in the British Industrial Revolution, 1760-1850. Routledge, London, UK, and New York, NY.

[15] Adam, S. (1776) The Wealth of Nations. Annotated Edition (2003), Bantam Classics, New York.

[16] Street, J.H. and James, D.D. (1982) Structuralism and Dependency in Latin America. Journal of Economic Issues, 16, 673-689. https://doi.org/10.1080/00213624.1982.11504027

[17] Lin, J.Y. (2009) Economic Development and Transition: Thought, Strategy, and Viability. Cambridge University Press, Cambridge. 
https://doi.org/10.1017/CBO9780511805622

[18] Long, C. and Zhang, X.B. (2011) Cluster-Based Industrialization in Financing and Performance. Journal of International Economics, 84, 112-123. https://doi.org/10.1016/j.jinteco.2011.03.002

[19] Murphy, K.M., Shleifer, A. and Vishny, R.W. (1989) Industrialization and the Big Push. Journal of Political Economy, 97, 1003-1026. https://doi.org/10.1086/261641

[20] Hartwell, R.M. (1965) The Causes of the Industrial Revolution: An Essay in Methodology. The Economic History Review, 18, 164-182.

[21] von Bertalanffy, L. (1924) Einfuhrung in Spengler's Werk. Literaturblatt KolnischeZeitung.

[22] Lin, Y. (2009) Systemic Yoyos: Some Impacts of the Second Dimension. Auerbach Publication, New York.

[23] Klir, G. (1985) Architecture of Systems Problem Solving. Plenum Press, New York. https://doi.org/10.1007/978-1-4757-1168-4

[24] Lin, Y. (1999) General Systems Theory: A Mathematical Approach. Plenum and Kluwer Academic Publishers, New York.

[25] National Research Council (1985) Mathematical Sciences: A Unifying and Dynamic Resource. Notices of the American Mathematical Society, 33, 463-479.

[26] Blauberg, I.V., Sadovsky, V.N. and Yudin, E.G. (1977) Systems Theory, Philosophy and Methodological Problems. Progress Publishers, Moscow.

[27] Klir, G. (2001) Facets of Systems Science. Springer, New York. https://doi.org/10.1007/978-1-4615-1331-5

[28] Lin, Y. (2007) Systemic Yoyo Model and Applications in Newton's, Kepler's Laws, etc. Kybernetes: The International Journal of Cybernetics, Systems and Management Science, 36, 484-516. https://doi.org/10.1108/03684920710747101

[29] Kline, M. (1972) Mathematical Thought from Ancient to Modern Times. Oxford University Press, Oxford.

[30] Wu, Y. and Lin, Y. (2002) Beyond Nonstructural Quantitative Analysis: Blown-Ups, Spinning Currents and Modern Science. World Scientific, River Edge. https://doi.org/10.1142/4877

[31] Lin, Y., Ma, Y. and Port, R. (1990) Several Epistemological Problems Related to the Concept of Systems. Mathematical and Computer Modelling, 14, 52-57. https://doi.org/10.1016/0895-7177(90)90146-E

[32] Lin, Y. and Forrest, B. (2011) Systemic Structure behind Human Organizations: From Civilizations to Individuals. Springer, New York.

[33] Forrest, Y.L.J. (2013) A Systemic Perspective on Cognition and Mathematics. CRC Press, Balkema.

[34] Forrest, Y.L.J. (2014) A Systems Perspective on Financial Systems. CRC Press, Balkema.

[35] Ying, Y.R. and Forrest, Y.L.J. (2015) Capital Account Liberation: Methods and Applications. CRC Press, New York.

[36] Forrest, Y.L.J., Buttermore, J. and Wajda, T.A. (2017) At Nash Equilibrium When New Market Competitions Appear? Kybernetes. the International of Cybernetics, Systems and Management Science, 46, 256-271.

[37] Bernheim, B.D. and Whinston, M.D. (1990) Multimarket Contact and Collusive Behavior. Rand Journal of Economics, 21, 1-26. https://doi.org/10.2307/2555490 
[38] Li, S.X. and Greenwood, R. (2004) The Effect of within Industry Diversification on Firm Performance: Synergy Creation, Multi-Market Contact and Market Structuration. Strategic Management Journal, 25, 1131-1153. https://doi.org/10.1002/smj.418

[39] Yu, T. and Cannella, A.A. (2012) A Comprehensive Review of Multimarket Competition Research. Journal of Management, 39, 76-109. https://doi.org/10.1177/0149206312462456

[40] Fuentelsaz, L. and Gómez, J. (2006) Multipoint Competition, Strategic Similarity and Entry into Geographic Markets. Strategic Management Journal, 27, 477-499. https://doi.org/10.1002/smj.529

[41] Haveman, H.A. and Nonnemaker, L. (2000) Competition in Multiple Geographic Markets: The Impact on Growth and Market Entry. Administrative Science Quarterly, 45, 232-267. https://doi.org/10.2307/2667071

[42] Hide, R. (1953) Some Experiments on Thermal Convection in a Rotating Liquid. Quarterly Journal of the Royal Meteorological Society, 79, 161. https://doi.org/10.1002/qj.49707933916

[43] Fultz, D., Long, R.R., Owens, G.V., Bohan, W., Kaylor, R. and Weil, J. (1959) Studies of Thermal Convection in a Rotating Cylinder with Some Implications for Large-Scale Atmospheric Motion. In: Fultz, D., Long, R.R., Owens, G.V., Bohan, W., Kaylor, R. and Weil, J., Eds., Studies of Thermal Convection in a Rotating Cylinder with Some Implications for Large-Scale Atmospheric Motions, Springer, Berlin, 1-104.

[44] Cipolla, C.M. (1994) Before the Industrial Revolution: European Society and Economy, 1000-1700. WW Norton \& Company, New York.

[45] Ebrey, P.B. (1999) The Cambridge Illustrated History of China. Cambridge University Press, Cambridge.

[46] Hui, V.T. (2004) Toward a Dynamic Theory of International Politics: Insights from Comparing Ancient China and Early Modern Europe. International Organization, 58, 175-205. https://doi.org/10.1017/S0020818304581067

[47] Petrovslaya, I., Zaverskiy, S. and Kiseleva, E. (2017) Attribute to Entrepreneurship in Russia: Three Dimensional Institutional Approach. Advances in Systems Science and Applications, 17, 29-43.

[48] Kriedte, P., Medick, H. and Schlumbohm, J. (1977) Industrialization before Industrialization: Rural Industry in the Genesis of Capitalism. Cambridge University Press, Cambridge.

[49] Shah, R., Mittal, H. and Gao, Z.J. (2014) Innovation, Entrepreneurship, and the Economy in the US, China, and India: Historical Perspectives and Future Trends. Academic Press, New York.

[50] Malthus, T.R. (1798) An Essay on the Principle of Population as It Affects the Future Improvement of Society. St. Paul's Church Yard, London.

[51] Landes, D.S. (1999) The Wealth and Poverty of Nations: Why Some Are So Rich and Some So Poor. W. W. Norton \& Company, Inc., New York.

[52] Gerschenkron, A. (1962) Economic Backwardness in Historical Perspective. Belknap Press of Harvard University Press, Cambridge.

[53] Clark, G. (2012) A Review Essay on the Enlightened Economy: An Economic History of Britain 1700-1850 by Joel Mokyr. Journal of Economic Literature, 50, 85-95. https://doi.org/10.1257/jel.50.1.85

[54] Allen, R.C. (2009) The British Industrial Revolution in Global Perspective. Cambridge University Press, Cambridge. https://doi.org/10.1017/CBO9780511816680 
[55] Clark, G. (2007) A Farewell to Alms: A Brief Economic History of the World. Princeton University Press, Princeton.

[56] Lucas, R.E. (2003) The Industrial Revolution: Past and Future. Working Paper of Federal Reserve Bank of Minneapolis.

[57] McCloskey, D.N. (2010) Bourgeois Dignity: Why Economics Can't Explain the Modern World. University of Chicago Press, Chicago. https://doi.org/10.7208/chicago/9780226556666.001.0001

[58] Mokyr, J. (2009) The Enlightened Economy: An Economic History of Britain 1700-1850. Yale University Press, New Haven.

[59] Morris, I. (2010) Why the West Rules for Now: The Patterns of History and What They Reveal about the Future. Profile Books, London.

[60] North, D. (1981) Structure and Change in Economic History. W. W. Norton, New York.

[61] Pomerranz, K. (2001) The Great Divergence: China, Europe, and the Making of the Modern World Economy. Princeton University Press, Princeton.

[62] Heaton, H. (2017) Industrial Revolution. In: Hartwell, R.M., Ed., The Causes of the Industrial Revolution in England, Routledge, London and New York, 30-52.

[63] Spirtes, P., Glymour, C. and Scheines, R. (2011) Causation, Prediction, and Search. MIT Press, Cambridge.

[64] Lipson, E. (1949) The Growth of English Society: A Short Economic History. A. and C. Black, London.

[65] Soros, G. (2003) The Alchemy of Finance. Wiley, New York.

[66] Crouzet, F. (2017) England and France in the Eighteenth Century: A Comparative Analysis of Two Economic Growth. In: Hartwell, R.M., Ed., The Causes of the Industrial Revolution in England, Routledge, London and New York, 139-174.

[67] McGrath, R.G. (2013) The End of Competitive Advantage: How to Keep Your Strategy Moving as Fast as Your Business. Harvard Business Review Press, Boston.

[68] Kyrkilis, D. and Simeon, S. (2015) Greek Agriculture's Failure-The Other Face of a Failed Industrialization-From Accession to EU to the Debt Crisis. Procedia Economics and Finance, 33, 64-77. https://doi.org/10.1016/S2212-5671(15)01694-9

[69] Stein, B. and Arnold, D. (2010) A History of India. 2nd Edition, Wiley-Blackwell, Oxford.

[70] Crespi, G., Giuliodori, D., Giuliodori, R. and Rodriguez, A. (2016) The Effectiveness of Tax Incentives for R \& D in Developing Countries: The Case of Argentina. Research Policy, 45, 2023-2035. https://doi.org/10.1016/j.respol.2016.07.006

[71] Kang, T.W., Beak, C.W. and Lee, J.D. (2017) The Persistency and Volatility of the Firm R \& D Investment: Revisited from the Perspective of Technological Capability. Research Policy, 46, 1570-1579. https://doi.org/10.1016/j.respol.2017.07.006

[72] Sabel, C. and Zeitlin, J. (1985) Historical Alternatives to Mass Production: Politics, Markets and Technology in Nineteenth-Century Industrialization. Past \& Present, 108, 133-176. https://doi.org/10.1093/past/108.1.133

[73] Smith, T.S. (1988) Native Sources of Japanese Industrialization, 1750-1920. University of California Press, Berkeley.

[74] Brandt, L., Ma, D.B. and Rawski, T. (2016) Industrialization in China. Institute for the Study of Labor, Discussion Papers IZA DP No. 10096.

[75] Clarkson, L.A. and Economic History Society (1985) Proto-Industrialization: The 
First Phase of Industrialization? Macmillan, London.

[76] Clarkson, L.A. (1996) Ireland 1841: Pre-Industrial or Proto-Industrial; Industrializing or Deindustrializing? In: Ogilvie, S.C. and Cerman, M., Eds., European Proto-Industrialization, Cambridge University Press, Cambridge, 67-84.

[77] Dosi, G., Grazzi, M. and Mathew, N. (2017) The Cost-Quantity Relations and the Diverse Patterns of "Learning by Doing": Evidence from India. Research Policy, 46, 1873-1886. https://doi.org/10.1016/j.respol.2017.09.005

[78] Kharas, H. and Kohli, H. (2011) What Is the Middle Income Trap, Why Do Countries Fall into It, and How Can It Be Avoided? Global Journal of Emerging Market Economies, 3, 281-289. https://doi.org/10.1177/097491011100300302

[79] Deane, P. (1979) The Evolution of Economic Ideas. Cambridge University Press, New York.

[80] Lin, Y. and OuYang, S.C. (2010) Irregularities and Prediction of Major Disasters. CRC Press, New York.

[81] Wielicka-Regulska, A., Gorynska-Goldmann, E. and Gazdecki, M. (2017) Theories and Typology of Goal Conflict in Food Consumption. Problemy Zarzadzania, 14, 109-124.

[82] Pinto Barbosa, A.S., Jovanovic, B. and Spiegel, M.M. (1997) Inequality and Stability. Annalesd Économieet de Statistique, No. 48, 15-40. https://doi.org/10.2307/20076095

[83] Asongu, S., Efobi, U. and Tchamyou, V. (2016) Globalization and Governance: A Critical Contribution to the Empirics. Munich Personal RePEc Archive, MPRA Paper No. 74229. https://doi.org/10.2139/ssrn.2800652

[84] Gillis, M., Perkins, D.H., Roemer, M. and Snodgrass, D.R. (1992) Economics of Development. W. W. Norton \& Company, New York.

[85] Arneson, R.J. (1990) Against Complex Equality. Public Affairs Quarterly, 4, 99-110.

[86] Bator, F.M. (1958) The Anatomy of Market Failure. The Quarterly Journal of Economics, 72, 351-379. https://doi.org/10.2307/1882231

[87] Grand, J.L. (1991) The Theory of Government Failure. British Journal of Political Science, 21, 423-442. https://doi.org/10.1017/S0007123400006244

[88] Cvetkovich, G. and Lofstedt, R.E. (1999) Social Trust and the Management of Risk. Earthscan from Routledge, New York.

[89] Lesourne, J. (1992) The Economics of Order and Disorder: The Market as Organizer and Creator. Clarendon Press, Oxford.

[90] Lakshmanan, J.R. and Hansen, W.G. (1965) A Retail Market Potential Model. Journal of the American Institute of Planners, 31, 134-143. https://doi.org/10.1080/01944366508978155

[91] Slater, S.F. and Narver, J.C. (1994) Market Orientation, Customer Value, and Superior Performance. Business Horizons, 37, 22-28. https://doi.org/10.1016/0007-6813(94)90029-9

[92] Del Monte, A. and Papagni, E. (2001) Public Expenditure, Corruption, and Economic Growth: The Case of Italy. European Journal of Political Economy, 17, 1-16. https://doi.org/10.1016/S0176-2680(00)00025-2

[93] Ashton, T.S. (1970) The Industrial Revolution, 1760-1830. Volume 38, CUP Archive. 


\section{Appendix}

Proof of Theorem 1. Without loss of generality, let us consider the aggregate of the incumbent firms as one firm, whose occupancy share of the market is $\alpha$ so that $\beta=1-\alpha$ represents the size of the market segment of switchers who base their purchase decision on which price is lower.

$(\Rightarrow)$ Suppose that by randomizing its price over the interval [0.1] a small firm enters into the oligopoly market of $m$ firms, which are collectively seen as one aggregate firm, because these $m$ firms are in a state of mutual forbearance. So, the consumer surplus must satisfy $\beta=1-\alpha>0$.

$(\Leftarrow)$ Assume that the consumer surplus satisfies $\beta=1-\alpha>0$. Firstly, let $\alpha_{0}$ be a real number so that $\beta=1-\alpha>\alpha_{0}>0$, and $\alpha=l \alpha_{0}$, where $l$ is a large natural number, indicating that the market has been largely taken by the incumbent firms.

Secondly, let us imagine that the aggregate firm is divided into $l$ many identical "firms", named $i, i=1,2, \ldots, l$. Each of them provides consumers with identical products and enjoys the market share $\alpha_{0}=\alpha / l$ of loyal consumers. These imaginary firms compete over the switchers with adjustable prices. Because these imaginary firms are really equal partitions of the same aggregate firm, they have the same constant marginal cost, which is set to zero without loss of generality, the managements of these firms are fully aware of the pricing strategies used by all the firms (because the firms are managed by the same administrative unit), and they establish their best, identical responses by playing the Nash equilibrium through their unified self-analyses.

Thirdly, these $l$ imaginary firms do not have any symmetric pure strategy Nash equilibrium. (For the setup here, there is no need to consider asymmetric pure strategy Nash equilibrium, because all these imaginary firms take identical actions). In fact, for any symmetric pure strategy portfolio $\left(x_{1}, x_{2}, \ldots, x_{l}\right)$, where $x_{i}=x_{j}$, for $i, j=1,2, \ldots, l$, a randomly chosen Firm $k(\in\{1,2, \ldots, l\})$ can slightly lower its price from $x_{k}$ to $y_{k}^{\prime}$ to produce additional profits for all the firms as long as $y_{k}^{\prime} \beta>\left(x_{k}-y_{k}^{\prime}\right) \alpha$, which is possible to do by adjusting $y_{k}^{\prime}$ sufficiently close to $x_{k}$. In such a case, the condition that the symmetric pure strategy portfolio $\left(x_{1}, x_{2}, \ldots, x_{l}\right)$ satisfies $x_{i}=x_{j}$, for $i, j=1,2, \ldots, l$, means that all of the $l$ imaginary firms slightly lowered their prices to $y_{k}^{\prime}$, creating more profits than before for these imaginary firms. So, $\left(x_{1}, x_{2}, \ldots, x_{l}\right)$ is not an Nash equilibrium. Even so, Forrest et al. [37] shows that these $l$ firms do have a symmetric mixed-strategy Nash equilibrium.

For the rest of this proof, it suffices to show that there is one small firm that will be expected to profit by entering this market through uniformly randomizing its price strategy over the interval [0.1].

Let $F(P)$ be the price distribution of Firm $j$, one of the imaginary firms of the aggregate firm. The aggregate firm or equivalently each of the $l$ imaginary forms sets its price after taking into account the price of the new firm and those of all other imaginary firms. Hence, the profits for Firm $j$ from its loyal consum- 
ers is $\alpha_{0} P$ and those from its share of the switchers is

$$
\prod_{i \neq j}^{l}(1-P)[1-F(P)] \beta P=\beta P(1-P)[1-F(P)]^{l-1} \text {. }
$$

Hence, the profits $\Pi$ Firm $j$ generates when the firm sells its product at price $P$ are

$$
\alpha_{0} P+\beta P(1-P)[1-F(P)]^{l-1}
$$

and the objective function of Firm $j$ is

$$
\begin{aligned}
\max _{F(P)} E(\Pi) & =\int_{-\infty}^{+\infty}\left\{\alpha_{0} P+\beta P(1-P)[1-F(P)]^{l-1}\right\} d F(P) \\
& =\int_{0}^{1}\left\{\alpha_{0} P+\beta P(1-P)[1-F(P)]^{l-1}\right\} d F(P)
\end{aligned}
$$

where $E(\Pi)$ stands for Firm $j$ s expected profits for all possible prices, and the objective for Firm $j$ is to maximize its expected profits by choosing its price distribution $F(P)$. The reason why the upper and lower limits of the integral are changed respectively from $+\infty$ and $-\infty$ to 1 and 0 is because when $P<0$ or when $P>1$, the profits are zero.

The equilibrium indifference condition of Firm $j$ is

$$
\alpha_{0} \times P+\beta \times P(1-P)[1-F(P)]^{l-1}=\alpha_{0} \times 1
$$

So, for the $l$ imaginary firms, solving Equation (1) leads to their symmetric equilibrium pricing strategy as follows:

$$
F(P)=1-\left(\frac{\alpha_{0}}{\beta P}\right)^{\frac{1}{l-1}}
$$

From $\beta>\alpha_{0}$, it follows that $\alpha_{0} / \beta<1$. So, for any Price $P$, satisfying $1 \geq P \geq \alpha_{0} / \beta$, Equation (2) is a well-defined probability distribution. This end implies that for the $l$ imaginary firms, or equivalently, the aggregate firm, the lowest allowed price is $\alpha_{0} / \beta$.

To complete this proof, it suffices to show that the small entrant actually expects to make profits in this new market. To this end because

$$
\lim _{P \rightarrow 1}-F(P)=1-\left(\alpha_{0} / \beta\right)^{1 /(l-1)} \neq F(1)=1,
$$

the cumulative price distribution function $F(P)$ has a jump discontinuity at the reservation value $P=1$, where the amount of jump is $\left(\alpha_{0} / \beta\right)^{1 /(l-1)}$. That is, $F(P)$ has a mass point of size $\left(\alpha_{0} / \beta\right)^{1 /(l-1)}$ at the reservation price $P=1$. So, the expected profits of the small entrant are the following:

$$
\begin{aligned}
E(\Pi) & =\int_{0}^{\alpha_{0} / \beta} \beta P d P+\int_{\alpha_{0} / \beta}^{+\infty} \beta P[1-F(P)]^{l} d P \\
& =\int_{0}^{\alpha_{0} / \beta} \beta P d P+\int_{\alpha_{0} / \beta}^{1} \beta P[1-F(P)]^{l} d P+\beta\left(\frac{\alpha_{0}}{\beta}\right)^{l /(l-1)}
\end{aligned}
$$

where the first term in the right-hand side of Equation (3a) stands for the expected profits of the small entrant when it charges the lowest price in the mar- 
ketplace and captures the entire segment of the switchers, and the second term is the small entrant's expected profits when it is in direct competition with the $l$ incumbent firms.

Because the first term in the right-hand side of Equation ( $3 b)$ satisfies

$$
\int_{0}^{\alpha_{0} / \beta} \beta P d P=\frac{\alpha_{0}^{2}}{2 \beta}>0
$$

the second term is $\geq 0$, because the integrant is positive and the third term is positive, it can be concluded that the expected profits of the small entrant $E(\Pi)$ is greater than zero. This end implies that if the consumer surplus $\beta=1-\alpha>0$, there will be at least one small entrant that will enter the market to compete with the incumbent firms. QED

Proof of Theorem 2. This market does not have any pure strategy Nash equilibrium and nonsymmetrical mixed strategy Nash equilibrium [37]. Let $F_{i}(P)$ stand for the price distribution of Firm $i, \in\{1,2, \ldots, m\}$, which compete with each other to attract switchers. The assumption that an increasing number of firms enter the market implies that the consumer surplus satisfies $\beta=1-\alpha>0$. Assume that there are $n$ new firms that enter the market by uniformly randomizing its price $P$ over the interval [0.1], where their cost basis is also assumed to be constant and set to zero. Then, the profits of incumbent Firm $i$ are given by

$$
\alpha P+\beta P(1-P)^{n} \prod_{j \neq i}^{m}\left[1-F_{j}(P)\right]
$$

and the objective function of incumbent Firm $i$ is

$$
\max _{F_{i}(P)} E\left(\Pi_{i}\right)=\int_{0}^{1}\left\{\alpha P+\beta P(1-P)^{n} \prod_{j \neq i}^{m}\left[1-F_{j}(P)\right]\right\} d F_{i}(P)
$$

The equilibrium indifference condition for incumbent Firm $i$ is

$$
\alpha \times P+\beta \times P(1-P)^{n} \prod_{j \neq i}^{m}\left[1-F_{j}(P)\right]=\alpha \times 1 .
$$

So, the symmetric equilibrium price strategy of each incumbent Firm $i, i=1$, $2, \ldots, m$, is

$$
F(P)=F_{i}(P)=1-P^{\frac{-1}{m-1}}(1-P)^{-\frac{n-1}{m-1}}\left(\frac{\alpha}{\beta}\right)^{\frac{1}{m-1}}=P^{\frac{-1}{m-1}}(1-P)^{-\frac{n-1}{m-1}} h(P)
$$

where $h(P)=P^{\frac{1}{m-1}}(1-P)^{\frac{n-1}{m-1}}-\left(\frac{\alpha}{\beta}\right)^{\frac{1}{m-1}}$.

For this strategy $F(P)$ to be valid, we must have $F(P)=0$, for $P \leq \underline{P}$, $F(P)=1$, for $P \geq \bar{P}$, and $F(P) \geq 0$, for $\underline{P} \leq P \leq \bar{P}$, where $\underline{P}$ and $\bar{P}$ are some fixed price levels such that $0 \leq \underline{P}<\bar{P} \leq 1$.

For such price levels $\underline{P}$ and $\bar{P}$ to exist, $h(P)$ must satisfy the following: $h(P) \geq 0$, for $\underline{P} \leq P \leq \bar{P}$, where $\underline{P}$ and $\bar{P}$ are some fixed price levels such that $0 \leq \underline{P}<\bar{P} \leq 1$, and that $h(0)<0$ and $h(1)<0$. Since

$$
h^{\prime}(P)=\frac{1}{m-1} P^{\frac{1}{m-1}}(1-P)^{\frac{n-1}{m-1}}\left[P^{-1}-(n-1)(1-P)^{-1}\right]
$$


it can be shown that $h(P)$ reaches its maximum at $P=1 / n$. That is, in order for the previously mentioned price levels $\underline{P}$ and $\bar{P}$ to exist, $h(P)$ must satisfy $h\left(\frac{1}{n}\right)>0$, which means

$$
\frac{\alpha}{\beta}<\frac{1}{n}\left(1-\frac{1}{n}\right)^{n-1}=\left(1-\frac{1}{n}\right)^{n}\left(1-\frac{1}{n}\right) \frac{1}{n} .
$$

So, when $n \rightarrow \infty, \alpha / \beta \rightarrow(1 / e) \times 1 \times 0=0$. This end means that the base of loyal customers for each incumbent firm gradually diminishes when an increasing number of new firms enter the market. QED 